\title{
National Patterns in Diabetes Screening: Data from the National Health and Nutrition Examination Survey (NHANES) 2005-2012
}

\author{
Meghan M. Kiefer, M.D., M.P.H. ${ }^{1,2}$, Julie B. Silverman, M.D., ${ }^{3,4}$, Bessie A. Young, MD. MPH ${ }^{3,4}$, and Karin \\ M. Nelson, M.D., M.S.H.S. ${ }^{1,3,4}$
}

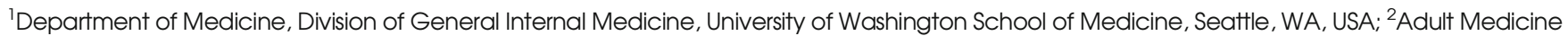
Clinic, Harborview Medical Center, Seattle, WA, USA; ${ }^{3}$ VA Puget Sound Healthcare System, Northwest HSR\&D Center of Excellence, Seattle, WA, USA; ${ }^{4}$ University of Washington School of Public Health, Department of Health Services, Seattle, WA, USA.

BACKGROUND: There are few current population-based estimates of the patterns of diabetes screening in the United States. The American Diabetes Association (ADA) recommends universal screening of adults $\geq 45$ years, and high-risk adults < 45 years, but there is no current assessment of ADA guideline performance in detecting diabetes and prediabetes. Furthermore, data on racial/ ethnic patterns of screening are limited.

OBJECTIVE: Our aim was to estimate diabetes screening prevalence for the US adult population and specifically for those who meet ADA criteria; to report the prevalence of prediabetes and diabetes among these groups; and to determine if high-risk race/ethnicity was associated with reported screening.

DESIGN: This was a Cross-sectional survey.

PARTICIPANTS: Non-pregnant adults ( $\geq 21$ years) without diabetes or prediabetes who participated in the $\mathrm{Na}$ tional Health and Nutrition Examination Survey (NHANES) in 2005-2012 $(n=17,572)$ were included in the study. "Screening-recommended" participants, classified by ADA criteria, included (1) adults $\geq 45$ years and (2) "high-risk" adults < 45 years. "Screening-not-recommended" participants were adults $<45$ years who did not meet criteria.

MAIN MEASURES: Diabetes screening status was obtained by self-report. We used calibrated $\mathrm{HbA}_{1 \mathrm{c}}$ and/or fasting glucose levels to define undiagnosed diabetes and prediabetes.

KEY RESULTS: Seventy-six percent of the study population (approximately 136 million US adults) met ADA criteria. Among them, less than half (46.2\%) reported screening; undiagnosed diabetes affected $3.7 \%$ (5 million individuals), and undiagnosed prediabetes affected $36.3 \%$ (49 million people.) African Americans were more likely to report screening, both among adults $\geq 45$ years and among "high risk" younger adults (OR 1.27 and 1.36, respectively.) Hispanic participants were also more likely to report screening (OR 1.31 for older adults, 1.42 for younger adults.) The screening rate among "screeningnot-recommended" adults was $29.6 \%$; the prevalence of diabetes and prediabetes were 0.4 and $10.2 \%$, respectively.

Received July 14, 2014

Revised October 23, 2014

Accepted November 14, 2014

Published online December 23, 2014
CONCLUSIONS: In a nationally representative sample, $76 \%$ of adults met ADA screening criteria, of whom fewer than half reported screening. Limitations include crosssectional design and screening self-report.

KEY WORDS: diabetes screening; prediabetes; NHANES; ADA; disparities. J Gen Intern Med 30(5):612-8

DOI: $10.1007 / \mathrm{s} 11606-014-3147-8$

(c) Society of General Internal Medicine 2014

\section{INTRODUCTION}

Type 2 diabetes mellitus (T2DM) is an important public health problem, and its associated morbidity and mortality can be lessened with early medication and lifestyle interventions. ${ }^{1-3}$ Screening for diabetes may have significant public health benefit, as patients with diabetes have a prolonged asymptomatic period, yet often have complications from their disease at the time of diagnosis. ${ }^{4}$ Although data have not shown a mortality benefit, ${ }^{5}$ it is plausible that earlier diagnosis via screening could mitigate some of these complications. In addition, prediabetes can be prevented or delayed from progressing to diabetes with lifestyle modifications and/or medication. ${ }^{6}$ Diabetes screening is recommended by several societies, including the United States Preventive Services Task Force (USPSTF), the Centers for Disease Control and Prevention (CDC), and the American Diabetes Association (ADA).

The ADA recommends diabetes screening every 3 years for all adults 45 years and older, as well as for overweight adults under 45 years with an additional risk factor, such as high-risk race/ethnicity, hypertension, hyperlipidemia, family history of diabetes, cardiovascular disease, or physical inactivity. ${ }^{7}$ However, the effectiveness of these guidelines in identifying adults with diabetes or prediabetes has not been well established, and it is unknown how many US adults meet these criteria. Finally, nearly all studies that have estimated screening prevalence have been in single centers or health management organizations, and have shown varying rates. ${ }^{8-10}$

There are known racial disparities in the burden of diabetes; non-white Americans have a higher prevalence of disease, ${ }^{11}$ worse glycemic control, ${ }^{12}$ higher rates of complications, ${ }^{13}$ and higher mortality. ${ }^{14}$ Nearly $3 \%$ of US adults have undiagnosed diabetes; rates are higher among non-Hispanic blacks and 
Mexican Americans. ${ }^{15,16}$ Whether this is due in part to decreased screening rates amongst those groups is not known. Previous smaller studies have demonstrated that age, female sex, and white race are associated with glycemic testing. ${ }^{17,18}$ A previous study of national screening patterns concluded that racial/ethnic minorities were less likely to report screening, ${ }^{19}$, but this did not include the most recent National Health and Nutrition Examination Survey (NHANES) data cycle, and analyses were not adjusted for insurance status or stratified by ADA guidelines.

The purposes of this study are (1) to evaluate the diabetes screening prevalence for the eligible US adult population and specifically for those that meet and do not meet ADA screening criteria; (2) to report the prevalence of prediabetes and diabetes among these groups; and (3) to determine which diabetes risk factors, including African American race and Hispanic ethnicity, are associated with screening.

\section{METHODS}

\section{Study Population and Data}

We conducted a retrospective cohort studying using data from four 2-year cycles of the National Health and Nutrition Examination Survey (NHANES), conducted between 2005 and 2012 by the National Center for Health Statistics, an agency of the Center for Disease Control and Prevention (CDC). Each cycle produces a representative sample of the civilian noninstitutionalized US population. Participants undergo a home interview as well as a separate examination and laboratory work. NHANES data collection is described elsewhere. ${ }^{20}$
Beginning in the 2005-2006 cycle, participants without a self-reported diagnosis of diabetes or prediabetes were asked if they had been tested for diabetes or "high sugar" within the past 3 years. Available demographic information included age, gender, race/ethnicity, education, and income. The race/ ethnicity categories are Non-Hispanic white (referred to as "white"), Non-Hispanic black (referred to as "African American"), Non-Mexican Hispanic, Mexican, and Other. We combined the Non-Mexican Hispanic and Mexican groups to form a "Hispanic" category.

Diagnoses such as hypertension, dyslipidemia, and stroke were defined by participant report of a physician diagnosis of the condition(s). Cardiovascular disease was defined as selfreporting of physician diagnosis of angina, myocardial disease, coronary artery disease or stroke. Family history of diabetes and insurance status were also obtained. Physical inactivity was defined in the 2005-2006 cycle as the least active response regarding the subject's daily activity level; all other responses were coded as physically active. For the 2007-2008 and subsequent cycles, physical inactivity was defined as reporting no vigorous or moderate activity, either at work or at home. All other responses were coded as physically active.

Examination data include multiple blood pressure readings, height, weight, and body mass index (BMI) calculations, as well as glycosylated hemoglobin $\left(\mathrm{HbA}_{1 \mathrm{c}}\right.$.) Across the NHANES study population, examination and laboratory data were collected on greater than $96 \%$ of those examined. ${ }^{1}$ Undiagnosed diabetes was defined as a fasting glucose $\geq 125 \mathrm{mg} / \mathrm{dL}$ or a $\mathrm{HbA}_{1 \mathrm{c}}$ of $>6.5 \%$. Undiagnosed prediabetes was defined as a fasting glucose of $100-124 \mathrm{mg} / \mathrm{dL}$ or a $\mathrm{HbA}_{1 \mathrm{c}}$ of $5.7-6.4 \%$.

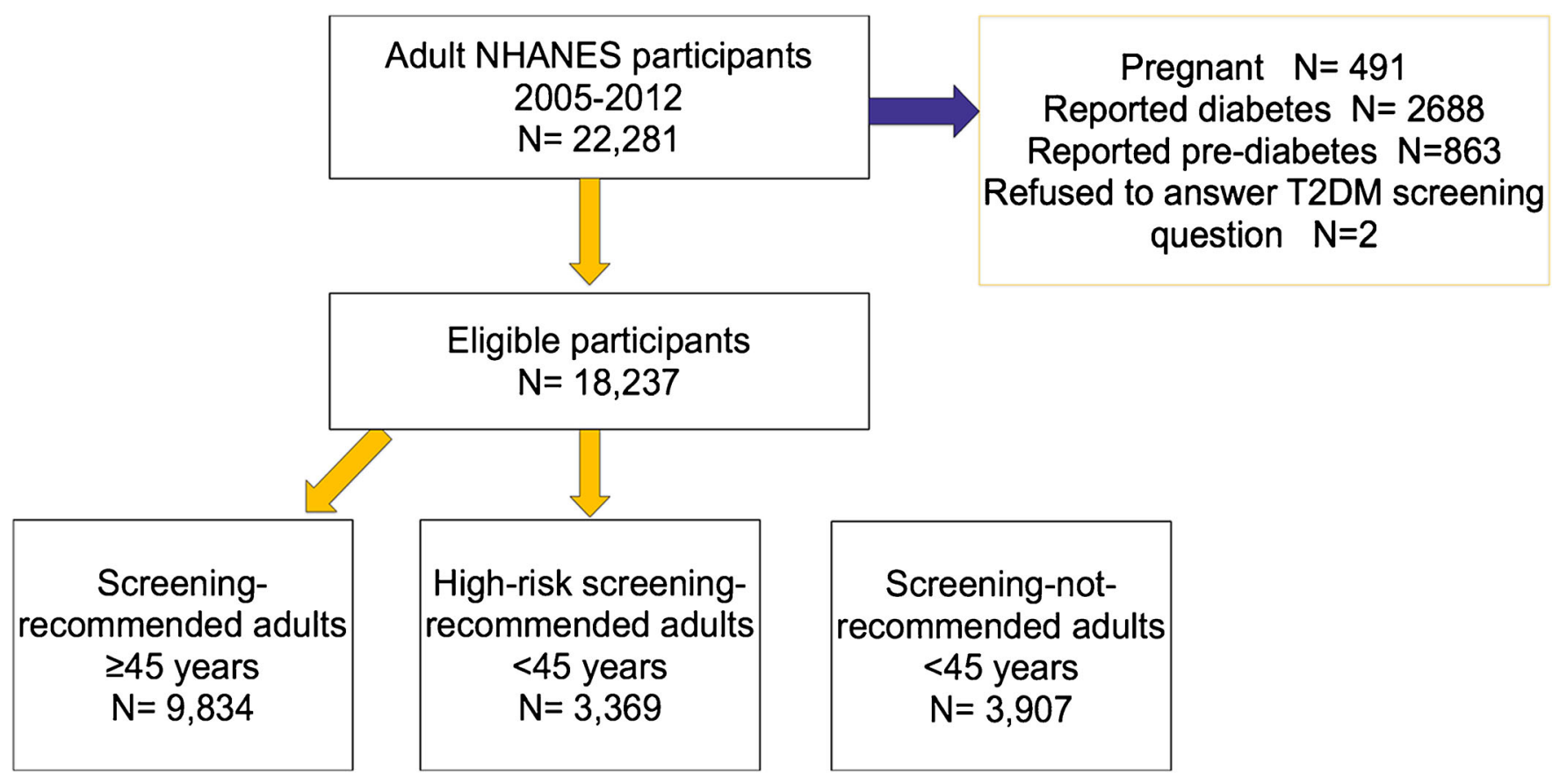

Figure 1. Flowchart of participants and classification by American Diabetes Association screening guidelines. 
The eligible population was defined as NHANES survey participants from 2005 to 2012 who were non-pregnant adults ( $\geq 21$ years), without a reported diagnosis of diabetes or prediabetes, who answered questions about diabetes screening. Persons with prediabetes were excluded because these participants were not asked about diabetes screening, and pregnant participants were excluded, as universal screening for gestational diabetes is an accepted recommendation and is a distinct entity outside the scope of this study.

The study population was classified by ADA criteria into "screening-recommended" and "screening-not-recommended" groups. "Screening-recommended" participants included (1) all adults $\geq 45$ years included in the study $(n=9,834)$ and (2) "high-risk" adults $<45$ years $(n=4,445)$. "High-risk" was defined as overweight adults $<45$ years who had at least one known additional risk factor for diabetes. "Screening-not-recommended" participants $(n=3,293)$ were adults $<45$ years who did not meet ADA screening criteria by available data. A further 665 study participants younger than 45 were missing either BMI or risk factor data, and their screening recommendation category could not be determined (Fig. 1).

\section{Statistical Analysis}

Data were analyzed using Stata 12.1 (STATA Corporation, College Station, TX, USA, 2006) and were weighted to account for the clustered, multistage probability sampling design. Sampling weights were used to calculate population estimates, and sampling strata and primary sampling units were accounted for to estimate variances and to test for significant differences. All results are presented as unweighted counts, weighted percentages or odds ratios.

Bivariate analyses using a chi-squared statistic were used to assess associations between sociodemographic characteristics and screening status. Multivariable logistic regression models were used to evaluate the association between screening and racial/ethnic group, with a priori adjustments for other screening indications as well as age, gender, and insurance status.

\section{RESULTS}

Between 2005 and 2012, 22,281 adult subjects participated in NHANES; of these, 491 were pregnant, 2,688 reported

Table 1. "Screening Appropriate" Population Characteristics, by Age

\begin{tabular}{|c|c|c|c|c|c|}
\hline & \multirow{2}{*}{$\begin{array}{l}\text { Total screening-eligible } \\
\text { population* } n=17,572 \\
(177,000,000)\end{array}$} & \multicolumn{3}{|c|}{ Screening-recommended } & \multirow{2}{*}{$\begin{array}{l}\text { Screening-not- } \\
\text { recommended } \\
n=3,293(41,500,000)\end{array}$} \\
\hline & & $\begin{array}{l}\text { Age } \geq 45 y \\
n=9,834 \\
(93,100,000)\end{array}$ & $\begin{array}{l}\text { High-risk < } 45 \text { y } \\
n=4,445(42,800,000)\end{array}$ & $\begin{array}{l}\text { Combined age } \geq 45 y \\
\text { and high-risk }<45 y \\
n=14,279(136,000,000)\end{array}$ & \\
\hline $\begin{array}{l}\text { Undiagnosed prediabetes } \\
(\%)\end{array}$ & 30.2 & 41.1 & 25.7 & 36.3 & 10.3 \\
\hline $\begin{array}{l}\text { Undiagnosed diabetes } \\
(\%)\end{array}$ & 2.9 & 4.4 & 2.2 & 3.7 & 0.4 \\
\hline $\begin{array}{l}\text { Report diabetes screening } \\
(\%)\end{array}$ & 42.4 & 50.0 & 37.9 & 46.2 & 29.6 \\
\hline Age (years) & 46.4 & 59.4 & 33.7 & 51.4 & 31.8 \\
\hline $\mathrm{HbA}_{1 \mathrm{c}}($ mean \%) & 5.4 & 5.6 & 5.4 & 5.5 & 5.2 \\
\hline BMI $\left(\right.$ mean $\left.\mathrm{kg} / \mathrm{m}^{2}\right) \dagger$ & 28.2 & 28.4 & 31.8 & 29.5 & 23.9 \\
\hline Female $(\%)$ & 51.2 & 52.9 & 45.9 & 50.7 & 53.0 \\
\hline Overweight (\%) & 33.9 & 37.3 & 47.8 & 40.6 & 11.7 \\
\hline Obese $(\%)$ & 31.7 & 32.4 & 52.2 & 38.7 & 9.1 \\
\hline \multicolumn{6}{|l|}{ Race/Ethnicity } \\
\hline White $(\%)$ & 69.1 & 77.6 & 47.1 & 68.0 & 73.2 \\
\hline African American (\%) & 10.9 & 9.2 & 18.2 & 12.1 & 7.3 \\
\hline Hispanic $(\%)$ & 13.3 & 7.9 & 27.7 & 14.2 & 10.6 \\
\hline Other $(\%)$ & 6.5 & 5.3 & 7.0 & 5.8 & 8.9 \\
\hline $\begin{array}{l}\text { Family history of } \\
\text { diabetes }(\%)\end{array}$ & 34.6 & 34.1 & 48.1 & 38.5 & 21.7 \\
\hline Hyperlipidemia (\%) & 35.4 & 45.3 & 31.7 & 41.7 & 10.9 \\
\hline Hypertension $(\%)$ & 27.3 & 40.3 & 21.4 & 34.3 & 4.4 \\
\hline $\begin{array}{l}\text { Cardiovascular disease } \\
(\%)\end{array}$ & 6.1 & 10.5 & 1.8 & 7.8 & 0.8 \\
\hline Physically inactive (\%) & 27.0 & 31.4 & 28.9 & 30.6 & 15.5 \\
\hline Current smoker $(\%)$ & 22.4 & 18.8 & 25.7 & 20.9 & 27.1 \\
\hline Income $>200 \%$ & 67.4 & 72.2 & 56.6 & 67.2 & 68.3 \\
\hline $\begin{array}{l}\text { Federal Poverty Level (\%) } \\
\geq \text { High school education } \\
(\%)\end{array}$ & 82.2 & 81.8 & 77.9 & 80.6 & 87.7 \\
\hline Insured $(\%)$ & 79.5 & 87.3 & 68.6 & 81.4 & 73.0 \\
\hline $\begin{array}{l}\text { No healthcare encounter } \\
\text { in past } 3 \text { years }(\%)\end{array}$ & 36.3 & 38.7 & 38.8 & 38.7 & 30.7 \\
\hline
\end{tabular}

* Subpopulation estimates may not sum precisely to population totals due to rounding error

$+H b A 1 c=$ glycosylated hemoglobin

$\ddagger B M I=$ body mass index $\left(\mathrm{kg} / \mathrm{m}^{2}\right)$

Numbers in parentheses are population estimates

When comparing the combined screening-recommended and screening-not-recommended groups, $p$ values for test of means (t-test) and test of homogeneity (chi-squared test) for all variables are $<0.0001$, with exception of female sex $(p=0.0535)$ and no recent healthcare encounter $(p=0.0008)$ 
diabetes diagnoses, 863 reported prediabetes, and two refused to answer questions regarding diabetes screening. For an additional 665 participants, a risk category could not be assigned due to incomplete data. The remaining 17,572 subjects serve as the study population (Fig. 1). The total "screening-recommended" group contained $74 \%$ of all US adults - approximately 136 million people. Fifty-one percent of eligible adults $<45$ years (approximately 42.8 million individuals) met ADA criteria for screening and were designated as "high-risk." Forty-nine percent of younger adults (approximately 41.5 million people) did not meet criteria and were considered "screening-not-recommended."

Table 1 displays the population characteristics of the total study population, screening-recommended adults, divided into older and "high-risk" younger adults, as well as younger adults for whom screening is not recommended. The prevalence of undiagnosed diabetes in the eligible population was $2.9 \%$, and the overall prevalence of undiagnosed prediabetes was $30.2 \%$. For adults 45 years and older, the rates of undiagnosed diabetes and prediabetes were 4.4 and $41.1 \%$, respectively. For highrisk adults under 45 , the prevalence of diabetes was $2.2 \%$, and the prevalence of prediabetes was $25.7 \%$. Finally, in those under 45 in whom screening was not recommended, the rate of diabetes was $0.4 \%$, and the rate of prediabetes was $10.3 \%$.

Adults 45 years and older had a mean HbAlc of $5.57 \%$ (95\% CI: 5.54, 5.59), higher than that of high-risk younger adults, whose mean HbAlc was $5.37 \%$ (95 \% CI: 5.35, 5.39). The mean $\mathrm{HbAlc}$ for screening-not-recommended younger adults was $5.16 \%$ (95\% CI: 5.14, 5.18). Compared to screening-recommended older adults, the high-risk younger adults had higher rates of obesity, physical inactivity, smoking tobacco, and family history of diabetes, but lower rates of hyperlipidemia, hypertension, and CAD (Table 1). High-risk younger adults were also more likely to have an income below $200 \%$ of the federal poverty level, less likely to have a high school degree, and less likely to be insured than older adults.

During the time period from 2005 to 2012, $42.4 \%$ of eligible adults $(95 \%$ CI: 41.1, 43.6) reported being tested for diabetes within the past 3 years. Fifty percent (95\% CI: 48.3, 51.7) of adults 45 and older and $37.9 \%$ (95\% CI: 36.3, 39.6) of high-risk younger adults reported screening. For the composite group of all adults who met ADA screening criteria, the overall rate of screening self-report was $46.2 \%$ (95\% CI: $44.8,47.6)$. Among adults in whom screening was not recommended, $29.6 \%$ (95\% CI: 28.0 31.2) reported being screened in the last 3 years.

Table 2 displays the bivariate associations of social, demographic, and health factors and diabetes screening status for all "screening-recommended" adults. Those who reported being screened had a higher burden of cardiovascular risk factors/ disease and were more likely to be older, to be female, to have an income $>200 \%$ of the federal poverty level, and to have a high school education. Screening-recommended persons who were not screened were more likely to be uninsured (24.9 vs. $12.3 \%$ ), without a recent healthcare encounter (44.3 vs.
Table 2. Characteristics of Those Who Report DM Screening or No Screening in Screening-Recommended Adults

\begin{tabular}{|c|c|c|c|}
\hline & \multicolumn{3}{|c|}{ Reporting Diabetes Screening } \\
\hline & $\begin{array}{l}\text { Yes }(\%) \\
n=7,515\end{array}$ & $\begin{array}{l}\text { No }(\%) \\
n=6,764\end{array}$ & p value \\
\hline Age (mean in years) & 55.1 & 51.0 & $<0.0001$ \\
\hline HbAlc ${ }^{\dagger}$ (mean) & 5.6 & 5.5 & $<0.0001$ \\
\hline Female sex & 55.4 & 46.7 & $<0.0001$ \\
\hline $\mathrm{BMI}+\left(\right.$ mean in $\left.\mathrm{kg} / \mathrm{m}^{2}\right)$ & 30.2 & 28.9 & $<0.0001$ \\
\hline Overweight & 38.2 & 42.8 & $<0.0001$ \\
\hline Obese & 42.9 & 35.1 & $<0.0001$ \\
\hline Race/Ethnicity & & & $<0.00001$ \\
\hline White & 70.2 & 66.0 & \\
\hline African American & 12.6 & 11.6 & \\
\hline Hispanic & 12.2 & 15.9 & \\
\hline Other & 5.1 & 6.6 & \\
\hline $\begin{array}{l}\text { Income }>200 \% \text { Federal } \\
\text { Poverty Level }\end{array}$ & 69.8 & 65.0 & $<0.0001$ \\
\hline$\geq$ High school education & 82.6 & 78.9 & $<0.0001$ \\
\hline Physically inactive & 31.5 & 29.8 & 0.0424 \\
\hline Current smoker & 17.8 & 23.6 & $<0.0001$ \\
\hline Family history of diabetes & 42.6 & 35.4 & $<0.0001$ \\
\hline Hyperlipidemia & 45.9 & 37.2 & $<0.0001$ \\
\hline Hypertension & 42.6 & 27.3 & $<0.0001$ \\
\hline Cardiovascular disease & 9.4 & 6.4 & $<0.0001$ \\
\hline Insured & 87.7 & 76.1 & $<0.0001$ \\
\hline $\begin{array}{l}>3 \text { years since healthcare } \\
\text { encounter }\end{array}$ & 14.3 & 44.3 & $<0.0001$ \\
\hline
\end{tabular}

Screening-recommended adults, as defined by ADA guidelines, includes all adults $>45$ years, and overweight adults $<45$ with additional risk factors

$+H b A 1 c=$ glycosylated hemoglobin

$\neq B M I=$ body mass index $\left(\mathrm{kg} / \mathrm{m}^{2}\right)$

$14.3 \%)$ and more likely to be current smokers (23.6 vs. $17.8 \%)$.

As seen in Table 3, among high-risk younger adults, African Americans had a $37 \%$ greater odds of reported diabetes screening when compared to whites (OR 1.37, $95 \% \mathrm{CI}$ : 1.09-1.72) when adjusted for insurance status, sex, and other indications for screening. Individuals of Hispanic ethnicity also had $43 \%$ greater odds of reporting screening (OR 1.43, 95\%CI: 1.16-1.76). In high-risk younger adults, female sex (OR 1.68, $95 \%$ CI 1.40-2.01), higher BMI (OR 1.04, $95 \%$ CI $1.02-1.06$ ), family history of diabetes (OR $1.28,95 \% \mathrm{CI}$ $1.04-1.66$ ) and having health insurance (OR 1.59, $95 \% \mathrm{CI}$ : $1.29-1.98)$ were also significantly associated with screening. Hypertension, hyperlipidemia, and physical inactivity were not significantly associated with report of screening.

In screening-recommended adults over 45 years, African American race was again associated with increased screening when compared to whites (OR 1.27, $95 \%$ CI: 1.11-1.44), as was Hispanic ethnicity (OR 1.30, $95 \%$ CI: $1.12-1.51$ ). In this model, older age (OR 1.01 [1.00-1.02]), higher BMI (OR 1.03, 95 \% CI: 1.01-1.04]), hypertension (OR 1.46, 95 \% CI: 1.26 1.70), hyperlipidemia (OR 1.32, $95 \%$ CI: $1.15-1.50$ ), family history of diabetes (OR 1.45, $95 \%$ CI: 1.27-1.66), and having health insurance (OR 1.60, $95 \% \mathrm{CI} ; 1.26-2.04)$ were all associated with higher screening odds. Physical activity and female sex were not associated with report of screening.

Among adults for whom screening is not recommended, Hispanic ethnicity was associated with screening (OR 1.68, 
Table 3. Odds of Reporting Being Screened for Diabetes Using Multivariate Logistic Regression

\begin{tabular}{|c|c|c|c|c|c|c|}
\hline & \multicolumn{4}{|l|}{ Screening recommended } & \multicolumn{2}{|c|}{ Screening-not-recommended } \\
\hline & \multicolumn{2}{|l|}{ Age 45 and older } & \multicolumn{2}{|c|}{ High-risk under 45 years } & \multirow[b]{2}{*}{ Odds ratio $(95 \%$ CI $)$} & \multirow[b]{2}{*}{$p$ value } \\
\hline & Odds ratio (95\% CI) & $p$ value & Odds ratio $(95 \%$ CI) & $p$ value & & \\
\hline \multicolumn{7}{|l|}{ Race/Ethnicity } \\
\hline White & 1.00 (ref) & & 1.00 (ref) & & 1.00 & \\
\hline African American & $1.27(1.11,1.46)$ & 0.01 & $1.37(1.09,1.72$ & 0.008 & $1.24(0.91,1.70)$ & 0.18 \\
\hline Hispanic & $1.30(1.12,1.51)$ & 0.01 & $1.43(1.16,1.76)$ & 0.001 & $1.68(1.23,2.28)$ & 0.001 \\
\hline Other & $1.10(0.88,1.45)$ & 0.48 & $0.91(0.67,1.25)$ & 0.57 & $1.18(0.83,1.67)$ & 0.35 \\
\hline Age (years) & $1.01(1.00,1.02)$ & 0.002 & $1.00(0.99,1.02)$ & 0.36 & $1.02(0.99,1.03)$ & 0.07 \\
\hline Female gender & $1.04(0.92,1.18)$ & 0.46 & $1.68(1.40,2.01)$ & $<0.001$ & $1.77(1.45,2.16)$ & $<0.001$ \\
\hline BMI $\left(\mathrm{kg} / \mathrm{m}^{2}\right)$ & $1.03(1.01,1.04)$ & $<0.001$ & $1.04(1.02,1.06)$ & $<0.001$ & $1.02(0.99,1.05)$ & 0.08 \\
\hline Hypertension & $1.46(1.26,1.70)$ & $<0.001$ & $1.24(0.99,1.55)$ & 0.06 & $1.35(0.83,2.19)$ & 0.22 \\
\hline Hyperlipidemia & $1.32(1.15,1.50)$ & $<0.001$ & $1.31(0.98,1.63)$ & 0.07 & $1.13(0.81,1.57)$ & 0.47 \\
\hline Family history of DM & $1.45(1.27,1.66)$ & $<0.001$ & $1.28(1.04,1.66)$ & 0.02 & $1.83(1.40,2.40)$ & $<0.001$ \\
\hline Physically inactive & $0.98(0.87,1.10)$ & 0.74 & $0.99(0.79,1.24)$ & 0.94 & $0.70(0.58,0.92)$ & 0.013 \\
\hline Insured & $1.60(1.26,2.04)$ & $<0.001$ & $1.59(1.29,1.98)$ & $<0.001$ & $1.77(1.35,2.32)$ & $<0.001$ \\
\hline
\end{tabular}

Models were adjusted for racelethnicity, age, sex, body mass index (BMI), hypertension, hyperlipidemia, family history of diabetes mellitus (DM), physical inactivity, and insurance status

$95 \%$ CI: 1.23-2.28) when compared with white race, and there were no statistical differences in odds of being screened between other racial/ethnic groups. In this group, female sex (OR 1.77, $95 \%$ CI: 1.45-2.16), family history of diabetes (OR 1.83, $95 \%$ CI: 1.40-2.40), and insurance status (OR 1.77, $95 \%$ CI: $1.35-2.32)$ were associated with screening. Physical inactivity, BMI, hypertension, and hyperlipidemia were not associated with screening. In a sensitivity analysis, hypertension was defined by including average measured blood pressure (systolic blood pressure $\geq 140 \mathrm{mmHg}$ or diastolic blood pressure $\geq 90 \mathrm{mmHg}$ ), and hyperlipidemia was defined by including those with a total cholesterol reading $\geq 200 \mathrm{mg} / \mathrm{dl}$ in self-reported diagnoses, and results of our models were unchanged (data not shown.)

Overall, in adjusted models of those who met screening guidelines, white race was associated with a $46.8 \%$ chance of being screened (95\% CI: 44.9, 48.7), African American race was associated with a $53.7 \%(95 \% \mathrm{CI}$ : 51.6, 55.7) predicted probability of screening, and Hispanic ethnicity was associated with a $53.9 \%$ probability of being screened (95\% CI: 51.2, 56.7).

\section{DISCUSSION}

In a nationally representative cohort, $41 \%$ of all nonpregnant US adults without known diabetes or prediabetes (approximately 75 million people) reported being screened for diabetes in the past 3 years. Of the 135 million Americans who met ADA criteria and did not have known diabetes or prediabetes, less than half (46\%) were screened for diabetes. It is worth emphasizing that persons who reported a diagnosis of diabetes or prediabetes were not asked about recent screening; many of these people may have been detected via screening in the past 3 years and could not be included in our analysis. However, even if all of the approximately 28 million Americans with diagnosed diabetes or prediabetes met ADA guidelines and were detected through screening, the overall screening rates within the "screening recommended group" would not exceed $56 \%$. Given the potential to inhibit progression of prediabetes ${ }^{6}$ and reduce microvascular complications, improving screening rates could be considered a public health priority. Screening younger and high-risk groups may be more costeffective than screening older persons ${ }^{21}$; given that approximately 26.6 million high-risk younger adults did not report screening, and 12 million low-risk younger adults reported it, restructuring our screening efforts to focus on those of higher risk while avoiding inappropriate screening may offer particular public health benefit.

The ADA guidelines in identifying persons at risk for diabetes may be compared to the narrower current USPSTF guidelines, which recommend screening those over 45 years with sustained blood pressure of $135 / 80 \mathrm{mmHg}$, and the proposed updated guidelines, which recommend screening for adults who are 45 years or older, overweight, or have a family history of diabetes. By our calculation, the ADA guidelines recommend screening for approximately $76.6 \%$ of the US adult population, or 136 million people. If implemented on a population-wide basis, these guidelines would capture $96.7 \%$ of individuals with abnormal $\mathrm{HbA} 1 \mathrm{c}$ or fasting glucose values. It is worth noting that the current USPSTF guidelines would recommend diabetes screening for an estimated $30.0 \%$ or 52.6 million people, and the proposed guidelines would increase that to $86.9 \%$ of the US population over 21 years of age, approximately 159 million people. These different guidelines, if implemented on a national scale, result in dramatically different screening patterns, which have important public health implications.

ADA criteria appear to appropriately discriminate between levels of risk for undiagnosed diabetes; those who did not meet screening criteria had only a $0.4 \%$ rate of diabetes, in contrast to the $4.4 \%$ and $2.2 \%$ rates in older and younger screeningrecommended groups. However, it is worth noting that $10.3 \%$ 
of those screening-not-recommended adults had undiagnosed prediabetes; if detecting prediabetes is a screening aim, universal screening may be more appropriate. Nonetheless, the implications of diagnosing nearly $30 \%$ of the adult population-over 50 million Americans-with a "pre-disease" warrant careful deliberation.

Across risk groups, having health insurance was associated with increased screening, highlighting the role of access to care in screening patterns. Physical activity was consistently not associated with screening, despite being an independent risk factor for diabetes. ${ }^{22}$ Across risk groups, hypertension, hyperlipidemia, increased BMI, and family history of type 2 diabetes were associated with screening, suggesting that US screening patterns are responsive to the increased risk associated with these factors, even if the overall proportion with such risk factors who are screened remains low. Finally, we found higher rates of screening in African American and Hispanic individuals, both in older adults (where high-risk race/ethnicity is not a screening criterion) and in younger adults (where it is considered a screening criterion.) This may differ from prior reports, ${ }^{19}$ given the use of newer NHANES data, adjustments for insurance status, and the reporting of screening rates only for the screening-eligible population, which was unaware of diabetes or prediabetes diagnoses.

Limitations of this study include the use of self-report of diabetes screening, which may not accurately reflect actual screening patterns. There are plausible mechanisms for both under-reporting (subjects who are unaware of screening as one of the purposes of blood draw or who do not recall being tested) and over-reporting (subjects may erroneously assume that screening was a component of a recent blood draw). While we cannot directly assess the reliability of the self-report using NHANES data, there are some indications that it can be considered valid. First, $94.1 \%$ of eligible participants who reported that they had not seen a health care provider within the last 3 years also denied screening for diabetes within that time frame. Further, numerous studies suggest that people diagnosed with diabetes are aware of their condition and can report it accurately. ${ }^{23-25}$ Regarding the accuracy of recalling diabetes screening, data are limited. However, for cholesterol screening, which is analogous in its mechanism of screening (blood draw, sometimes fasting), the available evidence indicates that screening recall (both of it being performed and of the results) is fairly reliable, ${ }^{26,27}$ although some data indicate that people tend to underreport such screening. ${ }^{26,28}$ This suggests that our estimates of screening prevalence may actually be an over-estimate. To our knowledge, there are no nationally representative data available for direct assessment of diabetes screening patterns, so while further work on both assessing the validity of self-report of diabetes screening and directly assessing provider screening patterns is needed, we believe that these data provide a useful starting point.
Survey data also do not allow for assessment of the some diabetes risk factors, such as a history of polycystic ovary syndrome, or clinical conditions associated with insulin resistance, such as acanthosis nigricans. Survey data additionally do not distinguish between testing for type 2 diabetes or gestational diabetes, allowing for potential misclassification. Our data are also restricted to NHANES survey cycles after 2005, when screening questions were first included in the survey. Previous screening patterns may have a disproportionate impact on current morbidity and mortality.

To our knowledge, this is the first report regarding diabetes screening rates within a national sample of US adults that is stratified by ADA risk groups, including those in whom screening is not recommended. This report characterizes national screening patterns by risk status and other sociodemographic factors, and examines the relationship between nonwhite ethnicity and disease screening. We additionally provide prevalence estimates for undiagnosed diabetes and prediabetes, stratified by ADA screening guideline categories of risk. Further understanding of the relationship between screening patterns and disease disparities is needed.

Acknowledgements: Funders: The first author's salary is provided by the Ruth L. Kirschstein National Research Service through the University of Washington; the work was also supported by resources from the VA Puget Sound Health Care System, Seattle WA. The funding sources had no role in the design, conduct, or analysis of the study, or the decision to submit the manuscript for publication.

Prior Presentations: This work was presented as a research abstract at the national Society for General Internal Medicine Conference on 25 April 2014.

Conflict of Interest: The authors declare that they do not have a conflict of interest.

Corresponding Author: Meghan M. Kiefer, M.D., M.P.H.; Adult Medicine ClinicHarborview Medical Center, 325 9th Avenue, Box 356420, Seattle, WA 98195-6420, USA (e-mail: meghanm@uw.edu).

\section{REFERENCES}

1. Effect of intensive blood-glucose control with metformin on complications in overweight patients with type 2 diabetes (UKPDS 34). UK Prospective Diabetes Study (UKPDS) Group. Lancet 1998;352:854-865.

2. Holman RR, Paul SK, Bethel MA, Matthews DR, Neil HAW. 10-year follow-up of intensive glucose control in type 2 diabetes. N Engl J Med. 2008;359: 1577-89.

3. Gaede $\mathbf{P}$, Lund-Andersen $\mathbf{H}$, Parving $\mathbf{H}-\mathbf{H}$, Pedersen $\mathbf{O}$. Effect of a multifactorial intervention on mortality in type 2 diabetes. $\mathrm{N}$ Engl $\mathrm{J}$ Med. 2008;358:580-91.

4. Bethel MA, Sloan FA, Belsky D, Feinglos MN. Longitudinal incidence and prevalence of adverse outcomes of diabetes mellitus in elderly patients. Arch Intern Med. 2007;167:921-7.

5. Simmons RK, Echouffo-Tcheugui JB, Sharp SJ, et al. Screening for type 2 diabetes and population mortality over 10 years (ADDITION-Cambridge): a cluster-randomised controlled trial. Lancet. 2012;380:1741-8.

6. Knowler WC, Barrett-Connor E, Fowler SE, et al. Reduction in the incidence of type 2 diabetes with lifestyle intervention or metformin. N Engl J Med. 2002;346:393-403.

7. American Diabetes Association. Standards of medical care in diabetes-2014. Diabetes Care. 2014;37(Suppl 1):S14-80. 
8. Ealovega MW, Tabaei BP, Brandle M, Burke R, Herman WH. Opportunistic screening for diabetes in routine clinical practice. Diabetes Care. 2004;27:9-12.

9. Kern LM, Callahan MA, Brillon DJ, Vargas M, Mushlin AI. Glucose testing and insufficient follow-up of abnormal results: a cohort study. BMC Health Serv Res. 2006;6:87.

10. Rifas-Shiman SL, Forman JP, Lane K, Caspard H, Gillman MW. Diabetes and lipid screening among patients in primary care: a cohort study. BMC Health Serv Res. 2008;8:25.

11. Centers for Disease Control and Prevention. Age-Adjusted Percentage of Civilian, Noninstitutionalized Population with Diagnosed Diabetes, by Race and Sex, United States, 1980-2011. Hyatsville, MD: National Center for Health Statistics. Available at: http://www.cdc.gov/diabetes/statistics/ $\mathrm{prev} /$ national/figraceethsex.htm. Accessed Nov 15, 2014

12. McWilliams JM, Meara E, Zaslavsky AM, Ayanian JZ. Differences in control of cardiovascular disease and diabetes by race, ethnicity, and education: U.S. Trends from 1999 to 2006 and effects of medicare coverage. Ann Intern Med. 2009; 150:505-15.

13. Lanting LC, Joung IMA, Mackenbach JP, Lamberts SWJ, Bootsma AH. Ethnic differences in mortality, End-stage complications, and quality of care among diabetic patients a review. Diabetes Care. 2005;28:2280-8.

14. Gu K, Cowie CC, Harris MI. Mortality in adults with and without diabetes in a National Cohort of the U.S. Population, 1971-1993. Diabetes Care. 1998;21:1138-45.

15. Fryar C, Hirsch R, Eberhardt M, Yoon S, Wright J. Hypertension, High Serum Total Cholesterol, and Diabetes: Racial and Ethnic Prevalence Differences in U.S. Adults, 1999-2006. Hyattsville, MD: National Center for Health Statistics. Available at: http://www.cdc.gov/nchs/data/databriefs/ db36.pdf. Accessed Nov 15, 2014

16. Hunt KJ, Gebregziabher M, Egede LE. Racial and ethnic differences in cardio-metabolic risk in individuals with undiagnosed diabetes: National Health and Nutrition Examination Survey 1999-2008. J Gen Intern Med. 2012;27:893-900.
17. Sheehy A, Pandhi N, Coursin DB, et al. Minority status and diabetes screening in an ambulatory population. Diabetes Care. 2011;34:1289-94.

18. Edelman D. Rate and predictors of glycemic testing of nondiabetic patients in a managed care population. Diabetes Care. 2001;24:957-9.

19. Casagrande SS, Cowie CC, Genuth SM. Self-reported prevalence of diabetes screening in the U.S., 2005-2010. Am. J. Prev. Med. 2014 Sep 15. [Epub ahead of print]

20. Centers for Disease Control and Prevention. NHANES response rates and population totals. Available at: http://www.cdc.gov/nchs/nhanes/ response_rates_CPS.htm. Accessed Nov 15, 2014.

21. The cost-effectiveness of screening for type 2 diabetes. CDC Diabetes CostEffectiveness Study Group, Centers for Disease Control and Prevention. JAMA. 1998;280:1757-1763.

22. Helmrich SP, Ragland DR, Leung RW, Paffenbarger RS. Physical activity and reduced occurrence of Non-insulin-dependent diabetes mellitus. N Engl J Med. 1991;325:147-52.

23. Comino EJ, Tran DT, Haas M, et al. Validating self-report of diabetes use by participants in the 45 and up study: a record linkage study. BMC Health Serv Res. 2013;13:481.

24. Day HR, Parker JD. Self-report of diabetes and claims-based identification of diabetes among Medicare beneficiaries. Natl Heal Stat Rep. 2013;69:1-14.

25. Jackson JM, DeFor TA, Crain AL, et al. Validity of diabetes self-reports in the Women's Health Initiative. Menopause. 2014;21:861-8.

26. Martin LM, Leff M, Calonge N, Garrett C, Nelson DE. Validation of selfreported chronic conditions and health services in a managed care population. Am J Prev Med. 2000;18:215-8.

27. Croyle RT, Loftus EF, Barger SD, Sun Y-C, Hart M, Gettig J. How well do people recall risk factor test results? Accuracy and bias among cholesterol screening participants. Health Psychol. 2006;25:425-32.

28. Fiscella K, Holt K, Meldrum S, Franks P. Disparities in preventive procedures: comparisons of self-report and Medicare claims data. BMC Health Serv Res. 2006;6:122-9. 